\title{
ESTRATÉGIAS DE MARKETINKG PARA O POSICIONAMENTO COMPETITIVO: ESTUDO DE CASO DA FARMÁCIA DE MANIPULAÇÃO MAGISTRAL PHARMA
}

\section{MARKETINKG STRATEGIES FOR COMPETITIVE POSITIONING: CASE STUDY OF PHARMA MAGISTRAL HANDLING PHARMACY}

Recebido em: 27/05/2018. Aceito em: 03/10/2018.

\author{
Aline de Carvalho Costa 1 \\ Késia Marques Soares ${ }^{2}$ \\ Luis Felipe de Oliveira Cavalcante ${ }^{3}$ \\ Fabiana da Silva Leite ${ }^{4}$
}

\section{RESUMO}

Para que as empresas se mantenham competitivas no mercado necessitam ter um posicionamento estratégico que oriente o crescimento da organização, independentemente do cenário econômico vigente. Uma das formas de buscar o posicionamento competitivo é através da elaboração de um plano estratégico de Marketing, que permita à organização analisar o seu ambiente interno e externo, redefinir os seus objetivos assim como a sua estrutura interna, por meio da reformulação da missão e visão, reconhecendo os seus pontos fortes e fracos, fazendo uso do Benchmarking para definir as estratégias a serem implementadas em relação ao mercado e à concorrência. $\mathrm{O}$ presente trabalho utilizou a metodologia de estudo de caso com o objetivo de analisar as melhores estratégias de Marketing a serem utilizadas na Magistral Pharma Farmácia de Manipulação LTDA-ME, localizada na cidade de Rio Bonito-RJ, propondo a aplicação da teoria na vivência de uma empresa, tendo como resultado o início do seu processo de reposicionamento no mercado.

Palavras-chave: Administração. Estratégia. Estratégias de Marketing. Posicionamento. Magistral Pharma.

\footnotetext{
1 Pós-Graduanda em Gestão Estratégica de Negócios pela Universidade Presbiteriana Mackenzie. E-mail: line87costa@gmail.com

2 Graduada em Administração pela Faculdade Cenecista de Rio Bonito (FACERB).

E-mail: kmsoares57@gmail.com

3 Mestrando em Economia e Gestão Empresarial pela Universidade Cândido Mendes (UCAM).

E-mail: luisfelipeadm@gmail.com

4 Doutoranda em Economia pela Universidade Federal Fluminense (UFF). Mestre em Economia e Gestão Empresarial pela Universidade Cândido Mendes (UCAM).

E-mail: fabianaleite@cnecri.com.br
} 


\section{ABSTRACT}

For companies remain competitive in the market they require a strategic position that guides the organization growth, regardless the current economic scenario. One of the ways of pursue competitive position is through the elaboration of a Marketing strategic plan that allows the company to analyze its internal and external environment, redefine its goals as well as its internal structure by means of the reformulation of the mission and the vision, recognizing its weak and strong, making use of the Benchmarking to define the strategies to be implemented in relation to the market and the competitiveness. The present work used the case study methodology with the aim of analyzing the best Marketing strategies to be used in the Magistral Pharma Farmácia de Manipulação LTDA-ME, located in the city of Rio Bonito-RJ, proposing the application of the theory of the experience of a company, having as result the beginning of its repositioning process in the market.

Keywords: Management. Strategy. Marketing Strategies. Positioning. Magistral Pharma.

\section{INTRODUÇÃO}

Na atual conjuntura econômica, as organizações enfrentam entraves para atuar de forma competitiva frente à concorrência, sendo necessário o reposicionamento de maneira estratégica por meio de ferramentas para atingir o seu público-alvo. Nesse processo de reestruturação empresarial são analisados os principais vetores do seu desempenho no mercado, identificando as lacunas existentes para visar melhorias em seus procedimentos.

Levitt (1960) afirma que as empresas precisam ter vontade de sobreviver e de satisfazer as necessidades dos seus clientes, porém para que se mantenham competitivas precisam adaptar-se as exigências do mercado antecipando-se à concorrência. Assim, através do Marketing e suas estratégias, as ferramentas são criadas na tentativa de atrair e fidelizar clientes para a conquista e manutenção do negócio (ROSA et al. 2013).

Devido ao cenário de instabilidades, voltou-se o olhar para a demanda empresarial de organizações que necessitassem de estratégias de posicionamento de mercado e marketing, que alavancassem de forma significativa a competitividade da empresa, aplicando-se a este contexto métodos que forneçam resultados de curto e médio prazo.

A partir das observações realizadas, em relação à dificuldade de posicionamento das empresas no mercado, percebeu-se uma oportunidade para investigar essa problemática empresarial na cidade de Rio Bonito-RJ, optando pela realização de um estudo voltado para uma organização do setor farmacêutico com deficiência em Marketing. $\mathrm{O}$ estudo tornou-se relevante devido à necessidade empresarial de acompanhar às tendências de mercado, implementando estratégias com foco no Marketing e buscando 
o posicionamento competitivo, pois o atual cenário é de organizações que desenvolvem ações com baixa atratividade para os consumidores locais.

O objetivo específico deste trabalho é realizar um estudo de caso, considerando a necessidade de análise e implementação das estratégias com a aplicação da teoria, utilizando ferramentas estratégicas desenvolvidas no Plano de Marketing para iniciar o processo de reposicionamento da empresa no mercado.

Neste estudo, a metodologia utilizada deu-se pela aplicação do Plano de Marketing com foco nas estratégias, por meio das ferramentas: Matriz SWOT, Composto de Marketing (4P's) e Benchmarking. Além de contar com um estudo de caso orientado pelo diagnóstico empresarial e pesquisa de campo que auxiliaram na escolha das melhores ferramentas a serem empregadas.

Além desta seção, o presente trabalho é composto por um Referencial Teórico que revisa os temas: Estratégia, Estratégia de Marketing e Posicionamento Competitivo, seguido pelo Estudo de Caso, Discussões e Resultados, e Considerações Finais.

\section{REFERENCIAL TEÓRICO}

As estratégias empresariais surgem com a finalidade de traçar os caminhos a serem seguidos para o alcance dos objetivos estabelecidos pela empresa. Quando se fala em estratégia, faz-se necessário uma associação do ambiente interno e externo, buscando como base as formas de maximização dos resultados organizacionais (PORTER, 2004; KOTLER e KELLER, 2007).

Porter (2004) ainda diz que a empresa, para obter um posicionamento promissor, deve adotar uma estratégia que leve em conta, de acordo com a escolha da organização, as variáveis de diferenciação, enfoque e liderança no custo total, com o intuito das forças competitivas serem enfrentadas pela empresa. A estratégia de diferenciação tem como objetivo tornar o produto ou serviço diferenciado em relação à concorrência, a de enfoque em segmentar os produtos e consumidores e a de liderança do custo total em reduzir os custos em relação à concorrência.

A estratégia competitiva é uma estruturação das metas e ações juntamente com as políticas que são necessárias para atingir os objetivos propostos, em que possuem a função de tornar a empresa mais competitiva através de um melhor posicionamento no mercado (PORTER, 2004; OLIVEIRA, 2014; KRIELOW e SANTOS, 2014).

O posicionamento é a forma de competir no mercado usando as estratégias e ferramentas de Marketing. Ao utilizar essas ferramentas a empresa seleciona, fornece e comunica o valor de seu produto para o mercado para que o consumidor perceba a marca/produto, diferenciando-o dos demais e agregando um valor maior a este com a utilização dos conceitos de Marketing e o seu composto como veículo de estratégia, influenciando o consumidor na decisão de compra de modo favorável para a organização (LIMA e CARVALHO, 2010; SAGAZ e FEIJÓ, 2015; OLIVEIRA e CAMPOMAR, 2007). 


\section{ESTRATÉGIA}

As estratégias são os meios de alcance dos objetivos, e sua formulação se dá entre a ação e o pensamento, sendo necessário reconhecer o que deve ser feito e explanar as possíveis formas de como realizá-lo (OLIVEIRA, 2014).

Vieira, Lavarda e Brandt (2016) relatam que as estratégias evoluíram das prescritivas para as descritivas, subtendendo que a estratégia não é algo que a empresa possui, mas sim o que ela faz. Dentro deste contexto observa-se que, a formulação da estratégia está ligada ao desenvolvimento da missão e visão por meio de uma análise detalhada do ambiente externo e interno (GIRALDI e CAMPOMAR 2005; KOTLER e KELLER, 2007).

Segundo Ansoff (1957), a estratégia possui particularidades para cada empresa. Após sua escolha, analisam-se os objetivos e a capacidade da organização em desenvolvê-la, mensurando os resultados por métodos qualitativos e quantitativos. Levitt (1960) diz que ao formular a estratégia as empresas devem ter uma visão macro para envolver a organização, motivando todos os envolvidos para o alcance dos objetivos.

Assim, as estratégias agem como norteadoras da organização para alcance dos seus objetivos, definindo as melhores formas de atingi-los.

\section{ESTRATÉGIAS DE MARKETING}

As Estratégias de Marketing devem desenvolver a marca e os seus produtos acompanhando o crescimento do setor. Estas estratégias não podem ser engessadas, pois a competição no mercado muitas vezes exige mudanças nas metas e objetivos empresariais, o que pressupõe o dinamismo na sua reformulação para que a empresa se mantenha competitiva no mercado (ARAGÃO, SOUZA NETO e BOAS, 2006).

O posicionamento, por sua vez, se relaciona com a segmentação de mercado, onde se identifica o público-alvo e se estuda como atingi-lo de forma eficaz (SAGAZ e FEIJÓ, 2015; TOLEDO e HEMZO, 1991). Dimingo (1988) diz que o posicionamento ainda tem uma via perceptiva - posicionamento psicológico - que é a forma de criar identidade, aparência da marca ou produto gerando percepção e distinção deste em relação aos concorrentes, o que ocorre por meio de um processo de conscientização e compreensão, despertando o interesse à atitude de comprar, realizada pelas ações das estratégias de Marketing.

O Plano de Marketing funciona como guia para direcionar e coordenar todos os objetivos de Marketing traçados pela organização (KOTLER e KELLER, 2007). O mesmo após ser formulado torna-se um plano de ações a serem concluídas por meio de várias atividades que possibilitem o alcance dos objetivos, traçando metas e implementando estratégias. Envolve a atividade gerencial, objetivos, habilidades e os recursos disponíveis, aproveitando assim as oportunidades de mercado. Esse é o primeiro passo para iniciar a formulação das estratégias no ambiente organizacional (GIRALDI e CAMPOMAR, 2005; TOLEDO, CAMPOMAR e TOLEDO, 2006; KOTLER e KELLER, 2007). 
Kotler e Keller (2007) afirmam que é através da declaração de Missão, Visão e Estratégias que as empresas constroem o seu Plano de Marketing. A partir da missão do negócio a organização analisa o ambiente interno e externo no qual se encontra, estabelece metas, formula e implementa as estratégias e controla o seu desempenho por meio do feedback.

Para a construção do Plano de Marketing, inicialmente realiza-se uma análise da situação da empresa por meio da Matriz SWOT - ferramenta estratégica que envolve o monitoramento dos ambientes externos e internos da empresa. No qual deve ser feito uma análise das forças macro e micro ambientais que atingem a capacidade organizacional de gerar lucros acompanhando tendências. Após essa análise, formulamse as melhores estratégias cruzando dados de forma que minimize os pontos negativos e maximize os positivos, contribuindo assim para o alcance dos resultados (KOTLER e KELLER, 2007; HSU et al. 2013; RODRIGUES et al. 2016).

$\mathrm{Na}$ sequência ocorre a implementação das estratégias, acompanhada de monitoramento dos resultados e observação dos desvios em relação aos valores de referência, tornando possível adotar medidas corretivas quando necessário. A partir da utilização de indicadores adequados, pode-se avaliar o avanço da organização de forma a reconhecer a efetividade das estratégias (KOTLER e KELLER, 2007).

O Composto de Marketing ou 4P's, como é conhecido, auxilia nas decisões empresariais e no posicionamento, sendo uma ferramenta estratégica que foca no cliente, suas necessidades, percepções e no processo de entrega de valor. Dentro do Composto de Marketing, o Produto é o que atende as necessidades dos clientes apresentando as suas características e especificidades. O Preço, por sua vez, está ligado ao seu custo, e a Promoção tem como objetivo ser o canal de comunicação entre o vendedor e comprador. A Praça, no Composto, possui por finalidade tornar o produto ou serviço acessível ao consumidor (DRUMOND e TOALDO, 2009; ROSA et al. 2013; TOLEDO, CAMPOMAR e TOLEDO, 2006).

Dentro do processo de implementação de melhorias organizacionais temos como estratégia de Marketing, o Benchmarking, que é uma ferramenta que visa um processo contínuo de comparações e melhorias, confrontando a organização com as práticas dos concorrentes, sendo uma forma de avaliar e melhorar os seus processos. Essa estratégia tem como principal finalidade proporcionar uma forma comparativa, não tendo como base a intenção de copiar e sim ter efetividade no alcance dos resultados por meio da implementação de ações consideradas de sucesso em outras organizações. O olhar comparativo de fora para dentro permite transformar estratégias externas em ações internas, adaptando-as à realidade das organizações e aprimorando o potencial competitivo da empresa (MENEGUELLI et al. 2007; CARLINI JUNIOR e VITAL, 2014). 


\section{POSICIONAMENTO COMPETITIVO}

O posicionamento é a projeção do produto e a imagem da empresa na mente do cliente, de forma que a organização possua vantagem em relação aos concorrentes, fazendo com que o consumidor identifique o produto ofertado e decida pela sua aquisição (KOTLER e KELLER, 2007).

O posicionamento competitivo consiste em construir uma proposta de valor da empresa para o consumidor, desta forma deve existir uma posição pretendida a fim de alcançar seus objetivos, porém devem ser definidas as estratégias empregadas no processo e ajustá-las de acordo com as necessidades da empresa, adequando-se as oportunidades existentes e se reposicionando no mercado. A base do posicionamento é uma comunicação bem estruturada e retroalimentada (DIMINGO, 1988; OLIVEIRA e CAMPOMAR, 2007).

Ao analisar o uso do posicionamento, vemos que este é uma ferramenta de apoio à decisão estratégica refletida na segmentação do mercado, aproveitamento e criação de oportunidades desenvolvidas através da oferta. O posicionamento é dividido por duas linhas de ação, o de mercado e o psicológico. $\mathrm{O}$ de mercado se dá com a seleção e segmentação do público-alvo e os seus concorrentes, reconhecendo os seus clientes e as suas expectativas de consumo. Já o posicionamento psicológico usa as ferramentas de Marketing para fixar a identidade da empresa/marca e do produto/serviço ao consumidor, a partir de uma proposta mental ligada à oferta, por meio da comunicação e promoção do produto, ocupando lugar de destaque no momento da compra (MORI NIÑO e GOUVÊA, 2004; DIMINGO, 1988; SERRALVO, PRADO e LEAL, 2006; TOALDO e LUCE, 2006).

\section{METODOLOGIA}

A presente pesquisa tem por objetivo desenvolver um Plano de Marketing observando as variáveis necessárias para o reposicionamento, a análise e a implementação de estratégias com foco em Marketing. O estudo foi desenvolvido em duas etapas: revisão teórica e estudo de caso para aplicabilidade da teoria.

Dentro do estudo de caso foram realizadas diversas entrevistas e reuniões com as áreas administrativa e gerencial da empresa analisada. Já na parte teórica, encontrase uma pesquisa de caráter exploratório com embasamento teórico e aprofundamento bibliográfico em referências da linha de pesquisa abordada.

No processo de levantamento de dados quantitativos para dar ênfase ao estudo de caso, foi realizada uma pesquisa com a população das cidades de Rio Bonito, Tanguá e Silva Jardim, buscando obter uma amostra com um percentual significativo para o mesmo. Foram aplicados questionários, através da ferramenta Google Forms, solicitando uma resposta por cada formulário disparado, de modo a não perder o caráter de 
veracidade das informações geradas pelo aplicativo, formando um banco de dados, onde gráficos são elaborados a partir das respostas obtidas.

\section{ESTUDO DE CASO}

\section{BREVE HISTÓRICO DA EMPRESA MAGISTRAL PHARMA}

A empresa do estudo de caso, Magistral Pharma, que atua no ramo farmacêutico teve sua primeira filial aberta na cidade de Rio Bonito-RJ, após os seus gestores perceberem que no município havia a possiblidade de crescimento e expansão para a empresa.

A Magistral Pharma atua no mercado com a revenda de remédios e produtos de marcas conhecidas que são encontrados, também, no espaço físico das grandes drogarias, além de trabalhar com um mix de produtos naturais.

\section{PESQUISA DE MERCADO}

A presente pesquisa foi realizada no parâmetro survey, tendo como base entrevistas por meio de questionários eletrônicos com perguntas padronizadas e fechadas sendo estes compostos por 15 perguntas que possibilitaram uma análise estatística. Devido às limitações em realizar uma pesquisa que abrangesse a população total, seguiu-se um padrão de obtenção de dados de uma amostra mais significativa possível.

Dentre os itens averiguados na pesquisa, observou-se que algumas questões se tornaram mais relevantes ao estudo proposto e à análise gerencial do posicionamento da empresa no mercado, possibilitando a escolha e implementação das melhores estratégias para iniciar o seu processo de reposicionamento.

A partir das perguntas realizadas no questionário, verificou-se que do total de entrevistados (Gráfico 1), 46,8\% responderam que já utilizaram os serviços da farmácia Magistral, contra 53,2\% que nunca utilizaram seus serviços. Esse percentual significativo pode ser composto por pessoas que realmente não utilizam produtos manipulados e por aqueles que utilizam produtos manipulados por outras farmácias. Nesse último caso, é preciso estabelecer uma estratégia de conversão de clientes. 
11. Você já utilizou os serviços da Farmácia de Manipulação Magistral de Rio Bonito?

(374 respostas)

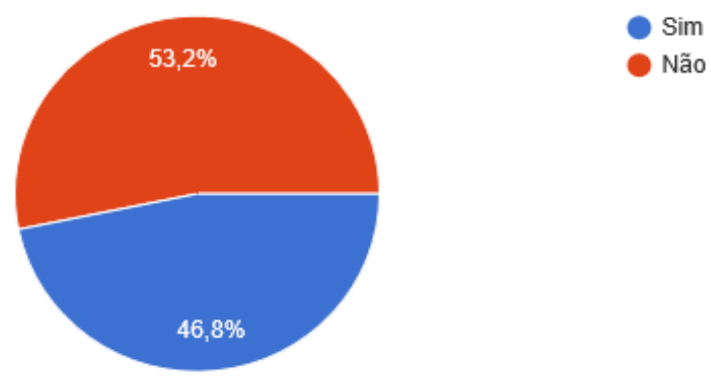

Fonte: Elaborado pelos autores.

A Magistral Pharma está localizada em uma área não central de Rio BonitoRJ. Por esse motivo, foi perguntado aos entrevistados (Gráfico 2) se a localização da farmácia interferia em sua decisão de compra e 58,5\% disseram que a localização atual da farmácia não interfere em sua decisão, mas para 22,6\% a localização é fator decisório, enquanto que $18,9 \%$ responderam que talvez a localização afete sua decisão de compra.

Gráfico 2 - Nível de influência da localização da Magistral Pharma

\section{A localização da Farmácia Magistral interfere na sua decisão de compra?} (349 respostas)

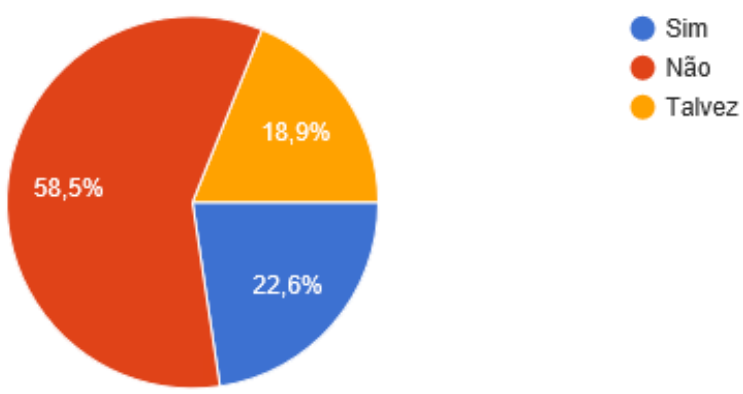

Fonte: Elaborado pelos autores.

Por ocasião da pesquisa, foi realizada uma pergunta para identificação do Top $O f$ Mind das farmácias de manipulação em Rio Bonito (Gráfico 3). Constatou-se que a Magistral Pharma possui a última posição na lembrança dos entrevistados. 
15. Quando você pensa em Farmácia de Manipulação, qual empresa vem em mente?

(352 respostas)

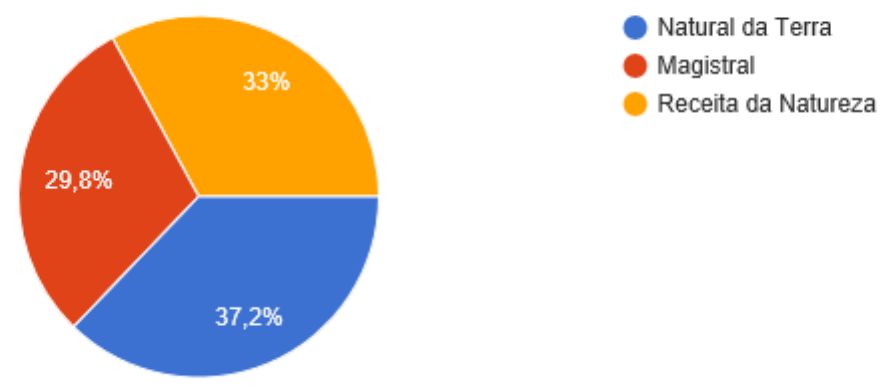

Fonte: Elaborado pelos autores.

Os dados fornecidos através da pesquisa permitiram identificar a percepção do público-alvo em relação à Magistral Pharma, enfatizando as suas deficiências e possibilitando melhorias em seus processos internos através do conhecimento obtido pelas informações geradas para que a Magistral Pharma alcance mais visibilidade, e consequentemente atraia um maior número de clientes.

\section{DISCUSSÕES E RESULTADOS}

O estudo de caso colaborou no processo de conhecimento e aplicação das estratégias de Marketing como ferramentas para iniciar o processo de reposicionamento da empresa de forma competitiva no setor, sendo este realizado em diferentes momentos. Na primeira etapa, foi realizado um diagnóstico da empresa que buscou a percepção interna e externa da Magistral Pharma, além de identificar o seu processo de comunicação, produção, logística e de Marketing. Já na segunda etapa, o foco seguiu na estruturação e implementação das estratégias na organização.

A partir de informações fornecidas pela empresa, percebeu-se que não existe definida uma estratégia de médio e de longo prazo, mas apenas ações de curto prazo, com caráter de reação às ações da concorrência e atendimento das necessidades imediatas.

Como primeiro elemento estratégico, a missão e a visão da empresa foram reformuladas delineando um novo enfoque gerencial para a empresa (Figura 1). 
Figura 1 - Reestruturação da Missão e Visão da Magistral Pharma Rio Bonito

\begin{tabular}{|c|c|c|}
\hline Magistral Pharma & Missão & Visão \\
\hline Antiga & $\begin{array}{l}\text { Manipular medicamentos de forma } \\
\text { personalizada, visando um tratamento } \\
\text { eficaz e proporcionando qualidade de } \\
\text { vida e bem estar aos nossos clientes e } \\
\text { colaboradores, mediante a prescrição } \\
\text { médica em conformidade com a } \\
\text { legislação vigente, empenhando } \\
\text { todos os esforços no desenvolvimento } \\
\text { de produtos. }\end{array}$ & $\begin{array}{l}\text { Ser reconhecidos como a melhor } \\
\text { farmácia com manipulação da região. }\end{array}$ \\
\hline Atual & $\begin{array}{l}\text { Oferecer produtos manipulados, } \\
\text { homeopáticos e naturais de qualidade } \\
\text { voltados para atender as necessidades } \\
\text { de saúde e bem-estar do consumidor, } \\
\text { buscando excelência baseada em } \\
\text { princípios éticos. }\end{array}$ & $\begin{array}{l}\text { Ser reconhecida como a melhor } \\
\text { Farmácia de Manipulação e } \\
\text { Homeopatia da cidade de Rio Bonito } \\
\text { e municípios vizinhos, inovando } \\
\text { continuamente os processos internos } \\
\text { e desenvolvendo melhorias para } \\
\text { contribuir na qualidade de vida dos } \\
\text { funcionários e consumidores. }\end{array}$ \\
\hline
\end{tabular}

Fonte: Elaborado pelos autores.

Logo após, na construção das estratégias, foi criado o Plano de Marketing, compreendendo a utilização das ferramentas estratégicas. Dentro desse plano, o feedback das ferramentas foi dado por meio de informações financeiras fornecidas pelo gestor e retroalimentadas através da percepção dos colaboradores.

A terceira etapa foi o de autoconhecimento da empresa e da sua concorrência. Dessa forma, foi feito um diagnóstico detalhado por meio da análise da Matriz SWOT, onde se analisou suas oportunidades e ameaças em seu ambiente externo, assim como suas forças e fraquezas no seu ambiente interno.

As forças encontradas na análise tiveram um destaque maior na divulgação por meio das mídias sociais, que proporcionaram uma propaganda informativa da qualidade dos produtos e da homeopatia e maximizou a produção interna com foco na redução do tempo.

Observando, junto aos gestores, que as oportunidades no comércio local são reduzidas para o setor farmacêutico, atentou-se para a mudança de hábitos dos consumidores ampliando o mix de produtos naturais e dos produtos de academia, devido à tendência de preocupação com a estética e a saúde.

Dentro da Matriz, foram reconhecidas fraquezas, como problemas no atendimento, na criação de layout para as embalagens, ausência de reuniões e feedbacks, parcerias e convênios, além da localização da empresa, embora, pela pesquisa de mercado realizada, esse fator não tenha sido considerado primordial pelo público-alvo. Como alternativas de melhorias foram apresentadas propostas de mudanças estratégicas aos gestores, como melhores práticas para potencialização dos seus processos internos, bem como convênios e parcerias para ampliação da sua participação no mercado. 
As ameaças detectadas na análise SWOT dificultam a empresa em se destacar no comércio local. Através do diagnóstico foi possível identificar as estratégias da concorrência e divulgar os produtos que podem ser fabricados sem prescrição médica devido à restrição normativa do setor. Já o fator aluguel foi analisado pela gestão da empresa para a redução de custos e em contrapartida teve como sugestão a minimização do valor dos produtos com compras corporativas em larga escala, tornando o preço competitivo e consequentemente aumentando o número de clientes.

Ao observar os aspectos para a execução do Composto de Marketing, foram feitas análises do Produto, focando na qualidade, confiança da matéria prima e deficiência em elaborar um layout inovador. No Preço, criaram-se estratégias de convênios de descontos, além de manter os preços competitivos cobrindo o orçamento da concorrência. Na Praça, ampliou-se as formas de atendimento ao cliente por meio dos orçamentos online com a utilização das ferramentas de Facebook e WhatsApp. E, por último, na variável Promoção, relacionou-se o uso de mídias sociais com divulgação de acordo com os períodos promocionais e sazonais, bem como promover comunicação direta com o cliente por meio de panfletagem em locais estratégicos.

O Benchmarkingfoi utilizado para realizar comparações em relação à concorrência de forma a introduzir ações internas que tornassem a empresa mais competitiva. A partir da observação das boas práticas da concorrência, foram formalizados convênios de descontos, venda de produtos sem prescrição médica - que não impliquem na sua produção -, visitas em clínicas médicas para a criação de parcerias com profissionais da região.

Como consequência destas estratégias, a empresa direcionou o seu foco para a eficiência no Marketing local, posicionando-se de forma competitiva ao ampliar o mix de produtos naturais e sua participação de mercado, direcionando os seus produtos para o público-alvo de academias por meio de convênios e parcerias realizadas onde, para fidelizar os seus clientes, fez-se a redução do tempo de fabricação dos produtos e melhorias no atendimento.

A partir da implementação de todas as estratégias apresentadas, dentro do período de 03 meses (março a maio), foi possível observar um crescimento da receita bruta total quando comparada com o mesmo período de 2015 e 2016, o que indica, a princípio, que as ferramentas de Marketing aplicadas na prática na Magistral Pharma geraram resultados financeiros positivos (Gráfico 4). 
Gráfico 4 - Demonstrativo da Receita Bruta do Período

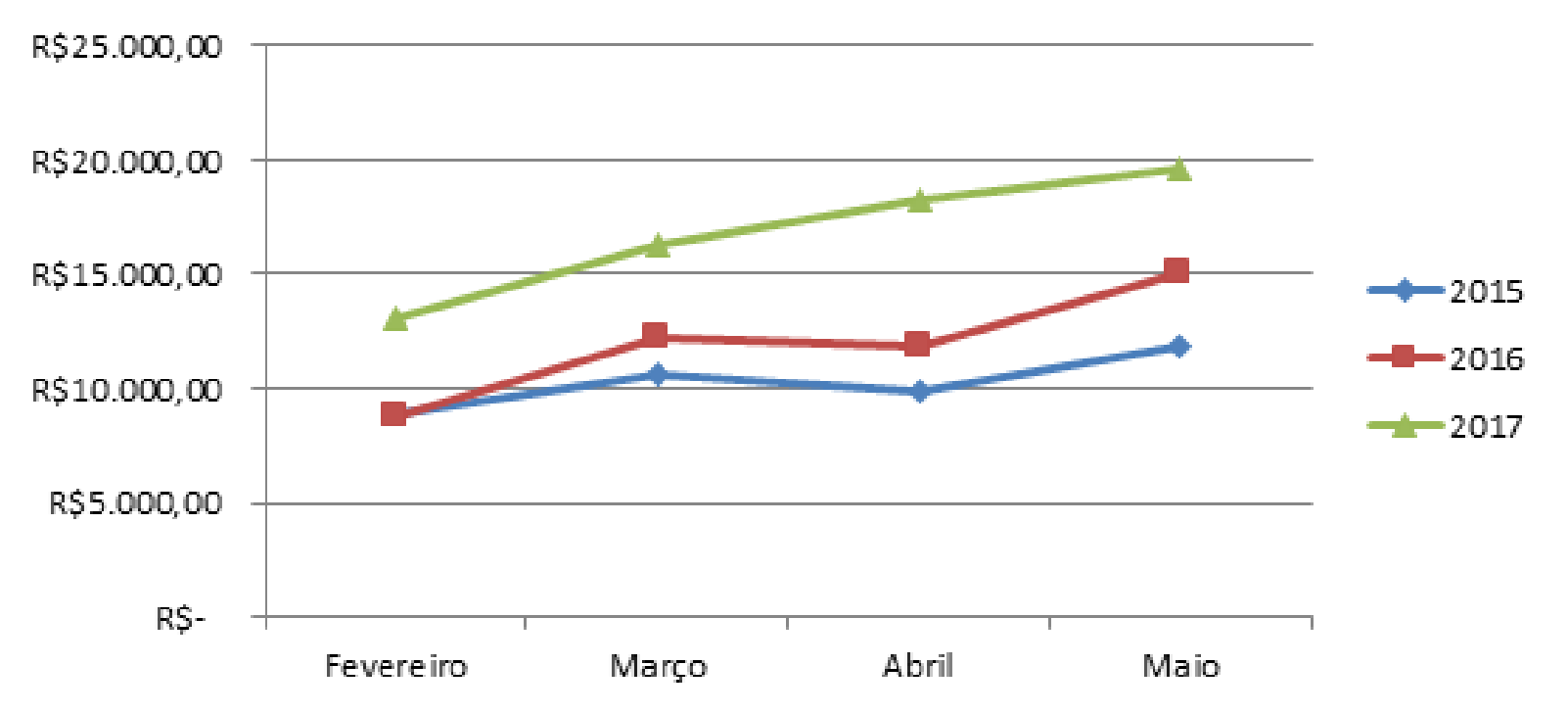

Fonte: Elaborado pelos autores.

\section{CONSIDERAÇÕES FINAIS}

Ao iniciar, junto aos gestores, o processo de reposicionamento da empresa no mercado de forma que possa competir com a concorrência, pode-se observar que é necessário fazer uso de estratégias de Marketing que a projetem de modo a criar uma imagem na mente dos consumidores, fortalecendo sua marca, aumentando sua participação no mercado e agregando, assim, valores significativos aos produtos e serviços ofertados pela organização.

O problema levantado no estudo foi analisado e buscou-se melhorias para mudar o quadro de deficiência em Marketing e posicionamento, de forma que a empresa entrou em um processo de crescimento através do reposicionamento iniciado por meio da aplicação das estratégias.

Os resultados apresentados no estudo sugerem que a elaboração de um Plano de Marketing e a implementação de ações estratégicas de comunicação adequadas ao público-alvo produzem resultados financeiros positivos para a instituição, que podem estar atrelados à melhoria da imagem da empresa diante do público, contribuindo para alavancar a competividadade da organização no setor. Onde, após o levantamento dos demonstrativos concedidos pelos gestores da farmácia, foi possível apurar no período empreendido do estudo, um aumento significativo direto na receita da Magistral Pharma. 


\section{REFERÊNCIAS}

ANSOFF, H. Igor. Estratégias Para diversificação. Harvard Business Review, Boston, USA, p.113-124, jun. 1957. Disponível em: <http://sgpwe.izt.uam. mx/files/users/ uami/sppc/130/Gestion_y_Control_Estrategico_I/Lectura_10._Ansoff_Igor_ Strategies_for_Diversification.pdf>. Acesso em: 27 fev. 2017.

ARAGÃO, Roberto Jorge Cruz de; SOUZA NETO, Silvestre Prado de; BOAS, Ana Alice Vilas. Gestão Estratégica de uma Indústria Farmacêutica de Sucesso. In: SEGET -SIMPÓSIO DE EXCELêNCIA EM GESTÃO E TECNOLOGIA, 3., 2006, Resende, Rj. Anais... . Resende, Rj: Aedb, 2006. p. 1 - 12. Disponível em: <http://inf. aedb.br/ seget/artigos06/619_ModeloSeget_Pfifer.pdf>. Acesso em: 20 fev. 2017.

CARLINI JUNIOR, Reginaldo José; VITAL, Tales Wanderley. A utilização do benchmarking na elaboração do planejamento estratégico: Uma importante ferramenta para a maximização da competitividade organizacional. Revista Brasileira de Gestão de Negócios, São Paulo, v. 6, n. 14, p.60-66, abr. 2014. Disponível em: <http://www. redalyc.org/articulo .oa?id=94761406>. Acesso em: 28 fev. 2017.

DIMINGO, Edward P.. The fine art of positioning: Sound bite or solid marketing?. Journal Of Business Strategy, Bingley, U.K., p.34-38, 1988. Disponível em:<http://www.artofpositioning.com/wp-content/uploads/2013/04/Fine-Art-OfPositio ning.pdf $>$. Acesso em: 23 fev. 2017.

DRUMOND, Maryângela; TOALDO, Ana Maria Machado. Implementação de Estratégias de Marketing, Competitividade e Fornecimento de Valor em PMEs. In: ENCONTRO DA ANPAD, 33., 2009, São Paulo. Anais... . São Paulo: Anpad, 2009. p.116. Disponível em: <http://www.anpad.org.br/admin/pdf/enanpad_2009_MKT348 .pdf>. Acesso em: 23 fev. 2017.

GIRALDI, Janaina de Moura Engracia; CAMPOMAR, Marcos Cortez. IMPLEMENTAÇÃO EFICAZ DE PLANOS DE MARKETING. - Revista Eletrônica de Gestão de Negócios, Santos, SP, v. 3, n. 1, p.37-55, dez. 2005. Disponível em: < http://www.unisantos.br/mestrado/gestao/egesta/artigos/43.pdf>. Acesso em: 20 fev. 2017.

HSU, Pang Lien et al. PROJETO DE ANÁLISE SWOT PARA DIAGNÓSTICO DO AMBIENTE COMPETITIVO DA EMPRESA NATURAL FARMA. In: SIMPÓSIO NACIONAL DE GESTÃO DE PROJETOS, 2., 2013, São Paulo. Anais... . São Paulo: Uninove, 2013. p.1-16. Disponível em: <http://repositorio.uninove.br/xmlui/ bitstream/ handle/123456789/398/333-671-1-DR_1_.pdf? sequence $=1>$. Acesso em: 20 fev. 2017. 
KOTLER, P. e KELlER K. L. Administração de Marketing. 12 ed. São Paulo: Pearson, 2007.

KRIELOW, Anderson; SANTOS, Moacir Rodrigues dos. A Definição do Posicionamento Estratégico sob a Perspectiva das Competências Organizacionais para Obtenção de Vantagem Competitiva. In: ENCONTRO DA ANPAD, 38., 2014, Rio de Janeiro. Anais... . Rio de Janeiro: Anpad, 2014. p.1-16. Disponível em: <http://www. anpad.org.br/admin/pdf/2014_EnANPAD_ESO1757.pdf>. Acesso em: 22 fev. 2017.

LEVITT, T. Miopia em marketing. 1960. Disponível em:<https://bsf.org.br/wpcontent/uploads/2015/08/levit_1960_miopia-em-marketing.pdf > Acesso em: 26 fev. 2017.

LIMA, Gustavo. Barbieri.; CARVALHO, Dirceu. Tornavoi. Estratégias de marketing e posicionamento de marca no setor hoteleiro: um estudo exploratório. Revista Brasileira de Marketing, v. 9, n. 3, p. 98-126, 2010. Disponível em:<http://www.revis tabrasileiramarketing.org/ojs-2.2.4/index.php/remark/article/view/2187> Acesso em: 23 fev. 2017.

MENEGUELLI, Marcelle Fernandes et al. BENCHMARKING: FERRAMENTA A SERVIÇO DA INOVAÇÃO. Revista Eletrônica da Faculdade Metodista Granbery, Juiz de Fora Mg, v. 3, n.1, p.1-16, dez. 2007. Disponível em: <http://re. granbery.edu.br/ artigos $/ \mathrm{MjAx}>$. Acesso em: 28 fev. 2017.

MORI NIÑO, Fanny; GOUVÊIA, Maria Aparecida. O PROCESSO DE POSICIONAMENTO ESTRATÉGICO NAS EMPRESAS DE SERVIÇOS TURÍSTICOS: UM ESTUDO DE CASO EM AGÊNCIAS DE VIAGEM DA CIDADE DE SÃO PAULO. Caderno de Pesquisa de Administração, São Paulo, v.1 1, n.11, p.63-79, mar. 2004. Disponível em: <http://www.unifal.com.br/Bibliotecas/ Artigos_Cientificos/O PROCESSO DE POSICIONAMENTO ESTRATÉGICO EM EMPRESAS DE TURISMO.pdf>. Acesso em: 24 fev. 2017.

OLIVEIRA, Braulio; CAMPOMAR, Marcos Cortez. Revisitando o posicionamento em marketing. Rege-Revista de Gestão, São Paulo, v.14, n.1, p.41-52, mar. 2007. Disponível em: <http://www. revistas.usp.br/rege/article/view/36589/39310>. Acesso em: 22 fev. 2017.

OLIVEIRA, Letícia de. A ESTRATÉGIA ORGANIZACIONAL NA COMPETITIVIDADE: UM ESTUDO TEÓRICO. Revista Eletrônica de Administração, Porto Alegre, v.10, n.4, p.1-23, ago. 2014. Disponível em: <http:// se r.ufrgs.br/index.php/read/article/view/41883/26496>. Acesso em: 22 fev. 2017.

PORTER, M. E. ESTRATÉGIA COMPETITIVA: Técnicas para análise de indústrias e da concorrência. 2 ed. Rio de Janeiro: Elsevier, 2004. 
RODRIGUES, Andrea et al. Planejamento estratégico de uma empresa do ramo Farmacêutico: Um estudo de Caso no município de Cantagalo- PR. In: SEMINÁRIO DE ENSINO, PESQUISA E EXTENSÃO DA UFFS, 1., 2016, Chapecó. Anais... Chapecó: Uffs, 2016. p.1-16. Disponível em: <https://www.convibra.com.br/dwp.as p? $\mathrm{id}=13343 \& \mathrm{ev}=109$. $>$. Acesso em: 21 fev. 2017.

ROSA, Ruy Roberto Porto Ascenso et al. VISÃO GERAL DAS FERRAMENTAS DE MARKETING E ANÁLISE DE SUA EFICÁCIA EM UM HOSPITAL DE REFERÊNCIA EM TERESINA-PI. Revista Inova Ação, Teresina, PI, v.2, n.2, p.122, dez. 2013. Disponível em: <http://www4.fsanet.com.br/revista/index.php/ inovaacao/article/view/492/pdf>. Acesso em: 26 fev. 2017.

SAGAZ, Sidimar Meira; FEIJÓ, Valéria Casaroto. POSICIONAMENTO ESTRATÉGICO DE MERCADO: UM ESTUDO DE CASO EM UM SALÃO DE BELEZA DO OESTE DE SANTA CATARINA. In: SEMINARIO INTERINSTITUCIONAL DE ENSINO, PESQUISA E EXTENSÃO, 20., 2015, Cruz Alta, Rs. Anais... . Cruz Alta, Rs: Unicruz, 2015. p.1-10. Disponível em: <https://www. unicruz.edu.br/seminario/anais/XX/Graduacao/Graduacao-TrabalhoCo mpletoSociaiseHumanidades/POSICIONAMENTOESTRATEGICODEMERCADO >. Acesso em: 26 fev. 2017.

SERRALVO, Francisco Antonio; PRADO, Karen Perrotta Lopes de Almeida; LEAL, Cirstine Andrade Musso. A Importância do Reposicionamento de Marcas no Contexto Competitivo: O Caso das Sandálias Havaianas. In: ENCONTRO DA ANPAD, 30., 2006, Salvador. Anais... . Salvador: Anpad, 2006. p.1-16. Disponível em: $<$ http://www. anpad.org.br/enanpad/2006/dwn/enanpad2006-mktc-1391.pdf>. Acesso em: 23 fev. 2017.

TOALDO, Ana Maria Machado; LUCE, Fernando Bins. Estratégia de marketing: contribuições para a teoria em marketing. Revista de Administração de Empresas, São Paulo, v.46, n.4, p.1-11, dez. 2006. Disponível em: <http://ww.s cielo.br/scielo. php? script=sci_arttext\&pid=So03475902006000400004 > . Acesso em: 24 fev. 2017.

TOLEDO, Luciano Augusto; CAMPOMAR, Marcos Cortez; TOLEDO, Geraldo Luciano. Planejamento de marketing e confecção do plano de marketing: uma análise crítica. Organizações \& Sociedade, Salvador, v.13, n.37, p.47-68, jun. 2006. Disponível em: $\quad<$ http://www.scielo.br/scielo.php?script=sci_arttext\&pid=S 1984-92302 006000200003>. Acesso em: 25 fev. 2017. 
TOLEDO, Geraldo Luciano; HEMZO, Miguel Angelo. O Processo de Posicionamento e o Marketing Estratégico. In: ENCONTRO ANUAL DA ANPAD, 15, 1991, Belo Horizonte. Anais... Belo Horizonte: Anpad, 199 1.p.1-17. Disponível em: <http:// each. uspnet.usp.br/mahemzo/Toledo, GL-Hemzo,MA-O_processo-de_posicionament o_e_o_Marketing-Estrategico.pdf>. Acesso em: 25 fev. 2017.

VIEIRA, Fernando Mendonça Alves; LAVARDA, Rosalia Aldraci Barbosa; BRANDT, Jaqueline Zermiani. Teoria e prática da estratégia: um estudo de caso. Tpa - Teoria e Prática em Administração, João Pessoa, v.6, n.1, p.195-22 1, jan. 2016. Disponível em: $<$ http://periodicos.ufpb.br/ojs/index.php/tpa/article/view/25822/15647> Acesso em: 22 fev. 2017. 